\title{
SUBMAKSIMALIŲ AEROBINIO PAJĖGUMO RODIKLIŲ PRIKLAUSOMUMAS NUO LETTOSIOS ADAPTACIJOS IR ERGOMETRIJOS SPECIFIKOS
}

\author{
Inga Pravdinskienė, Arvydas Stasiulis, Aleksandras Alekrinskis \\ Lietuvos kūno kultūros akademija, Kaunas, Lietuva
}

\begin{abstract}
Inga Pravdinskienė. Lietuvos kūno kultūros akademijos Taikomosios fiziologijos ir kineziterapijos katedros biologijos mokslų krypties
\end{abstract} doktorantè. Mokslinių tyrimų kryptis — sportininkų lètoji adaptacija ir ergometrijos specifika.

\section{SANTRAUKA}

Tyrimo tikslas — palyginti dviratininku, bėgiku, baidariu ir kanoju irkluotoju submaksimalius aerobinio pajėgumo rodiklius atliekant nuosekliai didinama krūvi skirtingais ergometrais.

Ištirta po septynis didelio meistriškumo dviratininkus (amžius - 19,7 (2,5) m., ūgis - 181,6 (6,6) cm, kūno masé 74,3 (10,0) kg, KMI - 22,5 (1,9)), bégikus (amžius - 22,6 (4,1) m., ūgis - 183,6 (5,2) cm, kūno masé - 75,1 (5,8) kg, KMI - 22,2 (1,8)), baidariu ir kanoju irkluotojus (amžius - 20 (1,2) m., ūgis - 183,7 (6,7) cm, küno mase — $82,6(5,1) \mathrm{kg}, \mathrm{KMI}-24,5(1,3))$. Skirtingomis dienomis tiriamieji atliko nuosekliai didinama krūvi (NDK) veloergometru, bègtakiu ir ranku ergometru. Norint nustatyti tiriamuju duju apykaitos rodiklius, nešiojamu duju analizatoriumi „, Oxycon Mobile“ (Vokietija) buvo registruojami kiekvieno kveppavimo ciklo rodikliai: deguonies suvartojimas (VO 2$)$, anglies dioksido išskyrimo greitis, plaučiu ventiliacija (VE) ir kt. Viso tyrimo metu 5 sekundžiu intervalais buvo registruojamas širdies susitraukimu dažnis (ŠSD) pulso matuokliu „,Polar S810“ (Suomija).

Dviratininku absoliučios ventiliacinio slenksčio (VS) reikšmès dirbant skirtingais ergometrais skyrèsi statistiškai reikšmingai ir buvo didžiausios dirbant veloergometru, mažesnès - bégtakiu, mažiausios — ranku ergometru. VE, ŠSD, $\mathrm{VO}_{2}$ rodikliai ties pirmu ir antru VS buvo didžiausi atliekant testa bègtakiu. Atliekant testa ranku ergometru, pirmas ir antras VS, juos atitinkančios absoliučios VE ir ŠSD reikšmès, absoliučios ir santykinès $V_{2} O_{2}$ reikšmés buvo mažesnès $(p<0,05)$ nei atliekant NDK veloergometru ir bègtakiu. Santykinès ŠSD reikšmès ties pirmu ir antru VS nesiskyrè. Bègiku VS ir dauguma juos atitinkančiu vegetaciniu sistemu funkciniu rodikliu buvo didžiausi bègant, mažesni - dirbant veloergometru, mažiausi - ranku ergometru. Dauguma irkluotoju rodikliu buvo didžiausi be்gant, mažesni - atliekant NDK veloergometru ir ranku ergometru. Šioje grupëje užfiksuota nedaug skirtumu tarp rodikliu dirbant ranku ergometru ir veloergometru.

Taigi atliekant NDK veloergometru, bėgtakiu ir ranku ergometru absoliučios VS reikšmès labiausiai priklauso nuo ergometro tipo ir tiriamojo lètosios adaptacijos pobūdžio, mažiausiai - santykinès (procentais nuo maksimaliu) $\mathrm{VO}_{2}$ ir ypač ŠSD reikšmés ties VS.

Raktažodžiai: adaptacijos specifiškumas, ventiliaciniai slenksčiai, deguonies suvartojimas, širdies susitraukimu dažnis, ergometro tipas.

\section{IVADAS}

$\mathrm{V}$ entiliaciniai slenksčiai (VS) yra svarbūs didelio meistriškumo ištvermę lavinančiu sportininkų aerobinio pajègumo rodikliai (Plato et al., 2008). VS leidžia prognozuoti daugelio ištvermès šakų (bėgimo, dviračių sporto, triatlono ir pan.) sportininkų varžybų rezultatus (Weltman, 1995). Atliekant nuosekliai didinamą krūvị (NDK) skirtingais ergometrais (veloergometru, bėgtakiu, ranku ergometru), VS ir juos atitinkantys vegetacinių sistemų funkcijos rodikliai skiriasi tiek nesportuojančių asmenų (Davis et al., 1976), tiek sportininku (Schneider et al., 1990). Atliekant NDK iqvairiais ergometrais, be pačių VS dažniausiai analizuojamos juos atitin- 
kančios absoliučios ir santykinès (procentais nuo maksimalių) plaučių ventiliacijos (VE), deguonies suvartojimo $\left(\mathrm{VO}_{2}\right)$ ir širdies susitraukimų dažnio (ŠSD) reikšmès. Tai svarbu testuojant įvairių šakų sportininkus, ypač tokių kaip triatlonas. Dozuojant aerobinių fizinių krūvių intensyvumą galima geriau suprasti ryši tarp bendrosios ir specifinès adaptacijos. Nevisiškai aišku, kaip minèti rodikliai priklauso nuo naudojamo ergometro tipo ir tiriamų sportininkų lètosios adaptacijos prie fiziniu krūvių ypatumų, ypač lyginant tų pačių tiriamuju fiziologinių pokyčių rodiklius atliekant NDK trim skirtingais ergometrais.

Tyrimo tikslas - palyginti dviratininkų, bėgiku ir baidarių irkluotojų submaksimalius aerobinio pajègumo rodiklius atliekant NDK skirtingais ergometrais.

\section{TIRIAMUUU KONTINGENTAS IR TYRIMO METODAI}

Tiriamieji. Ištirti didelio meistriškumo dviratininkai $(n=7)$, irkluotojai $(n=7)$ ir bègikai $(n=7)$. Jie buvo supažindinami su tyrimo eiga. Tyrimo protokolas aptartas ir patvirtintas Kauno regioniniame biomedicininių tyrimų etikos komitete.

Tiriamuju amžiaus, antropometrinių rodiklių vidurkiai ir standartinis nuokrypis pateikti 1 lentelèje.

Spirometrija. Norint nustatyti tiriamujų dujų apykaitos rodiklius, nešiojamu dujų analizatoriumi „Oxycon Mobile“ (Vokietija) buvo registruojami kiekvieno kvėpavimo ciklo rodikliai: $\mathrm{VO}_{2}, \mathrm{VCO}_{2}$, $\mathrm{VE}$, kvèpavimo koeficientas (RER), $\mathrm{O}_{2}$ ir $\mathrm{CO}_{2}$ slègis ore iškvėpimo pabaigoje $\left(\mathrm{PETO}_{2}\right.$ ir $\left.\mathrm{PETCO}_{2}\right)$. Užregistruotų rodikliu vidutinès reikšmès kas 5 sekundes buvo analizuojamos taikant Microsoft Excel programa.

Pulsometrija. Viso tyrimo metu širdies susitraukimų dažnis buvo registruojamas 5 sekundžiu intervalais pulso matuokliu „Polar S810“ (Suomija), vèliau analizuojamas taikant Microsoft Excel programa.
Biocheminė kraujo analizė. Norint nustatyti tiriamujų laktato koncentraciją kraujyje buvo imami kapiliarinio kraujo mėginiai iš rankos piršto. Kraujas imamas penktą ir dvidešimtą minutę po tyrimo, tiriamiesiems esant ramybès būsenos. Laktato koncentracija kraujyje buvo nustatoma naudojant modifikuotą analizatorių „Accutrend Lactate" (Germany).

Nenutrūkstamo nuosekliai didinamo krūvio (NDK) testas. Kiekvienas tiriamasis atliko tris NDK skirtingais ergometrais. Tuo tikslu tiriamieji atliko šešių minučių pramankštą: veloergometru „Monark 834E“ (Švedija), kai darbo galingumas siekė $70 \mathrm{~W}$, sukimo dažnumas $-70 \mathrm{k}$. / min; rankų ergometru - $17 \mathrm{~W}$, sukimo dažnumas 70 k. / min, bėgtakiu $-7 \mathrm{~km} / \mathrm{h}$ greičiu. Pailsèję penkias minutes, tiriamieji atlikdavo NDK veloergometru, bėgtakiu arba rankų ergometru. Atliekant testą veloergometru, krūvis buvo automatiškai didinamas kas $5 \mathrm{~s}$ po $2 \mathrm{~W}$. Testas nutraukiamas tada, kai tiriamasis nebegalèdavo atlikti kito krūvio nemažindamas sukimo dažnumo. Atliekant testą bėgtakiu, krūvis buvo automatiškai didinamas kas $6 \mathrm{~s}$ po $0,1 \mathrm{~km} / \mathrm{h}$. Maksimalusis juostos sukimosi greitis $-20 \mathrm{~km} / \mathrm{h}$. Takelio pasvirimo kampas automatiškai didèdavo po $0,5 \%$. Testas buvo nutraukiamas tada, kai tiriamasis nebegalèdavo bègti bėgimo takelio juostos sukimosi greičiu. Atliekant testą rankų ergometru, krūvis buvo didinamas kas $20 \mathrm{~s}$ po $100 \mathrm{~g}(0,1 \mathrm{~g} \times 70 \mathrm{k}$. / min $)$. Testas buvo nutraukiamas tada, kai tiriamasis negaledavo atlikti kito krūvio nemažindamas sukimo dažnumo. Po testo tiriamasis 5 minutes ilséjosi gulèdamas. Viso testo metu nešiojamu dujų analizatoriumi „Oxycon Mobile“ (Vokietija) buvo registruojami tiriamuju dujų apykaitos rodikliai. Pagal jų priklausomybę nuo atliekamo krūvio galios vèliau buvo nustatomi VS, juos atitinkančios $\mathrm{VO}_{2}$, ŠSD, VE reikšmès.

Tyrimo eiga. Tyrimas atliktas Lietuvos kūno kultūros akademijos (LKKA) Sporto fiziologijos laboratorijoje. Tyrimas vyko trim etapais. Pirmo tyrimo metu tiriamieji atliko nenutrūkstamą nuosekliai didinamo krūvio testą veloergometru, antro

\begin{tabular}{|c|c|c|c|c|}
\hline $\begin{array}{ll}\text { Rodikliai } & \text { Tiriamieji } \\
\end{array}$ & Bègikai & Dviratininkai & Irkluotojai & $\begin{array}{l}1 \text { lentelè. Tiriamųjų antropometri- } \\
\text { nių duomenų vidutinès reikšmès } \\
\text { ir standartiniai nuokrypiai }\end{array}$ \\
\hline Imtis, $\mathrm{n}$ & 7 & 7 & 7 & \\
\hline Amžius, m. & $22,6(4,1)$ & $19,7(2,5)$ & $20(1,2)$ & \\
\hline Ūgis, cm & $183,6(5,2)$ & $181,6(6,6)$ & $183,7(6,7)$ & \\
\hline Kūno masè, kg & $75,1(5,8)$ & $74,3(10,0)$ & $82,6(5,1)^{*}$ & \\
\hline KMI (kūno masės indeksas) & $22,2(1,8)$ & $22,5(1,9)$ & $24,5(1,3)$ & $\begin{array}{l}\text { Pastaba. }( \pm S) \text { - standartinis nuokrypis; } \\
\text { * - statistinis rodikliu reikšmingumas }\end{array}$ \\
\hline $\mathrm{VO}_{2 \max }, 1 / \min$ & $4,75(0,14)$ & $4,61(0,50)$ & $4,84(0,46)$ & $(\mathrm{p}<0,05)$ tarp bėgikų ir irkluotoju, \\
\hline $\mathrm{VO}_{2 \max }, \mathrm{ml} / \mathrm{kg} / \mathrm{min}$ & $64,49(6,07)$ & $65,47(4,72) \#$ & $58,70(4,93)$ & \# - tarp dviratininku ir irkluotojų gru- \\
\hline Forsuota iškvėpimo talpa, 1 & $5,53(0,22)$ & $5,58(0,57)$ & $5,98(0,54)^{*}$ & pių. \\
\hline
\end{tabular}


metu, po savaitès - nenutrūkstamą nuosekliai didinamo krūvio testą rankų ergometru, trečio metu - testą bègtakiu. Prieš tyrimą sportininkai turedavo kelias dienas aktyviai nesportuoti, tyrimo dieną neatlikti jokio fizinio krūvio. Prieš tyrima sportininkai turèdavo 2 valandas nevalgyti.

Matematinè statistika. Naudodami kompiuterinę programą Microsoft Excel apskaičiavome aritmetinius vidurkius ir standartinius nuokrypius. Skirtumų tarp grupių ar ergometrų tipo reikšmingumas buvo nustatomas taikant neparametrinius testus. Statistinių hipoteziu patikimumui nustatyti pasirinkome reikšmingumo lygmeni $p<0,05$. Visi statistiniai skaičiavimai atlikti naudojant programini paketą Statistica for Windows.

\section{REZULTATAI}

Dviratininkų absoliučios VS reikšmès dirbant skirtingais ergometrais skyrèsi statistiškai reikš- mingai ir buvo didžiausios dirbant veloergometru, mažesnès - bègtakiu, mažiausios - ranku ergometru. VE, ŠSD, $\mathrm{VO}_{2}$ ties pirmu ir antru VS buvo didžiausi atliekant testą bėgtakiu. Atliekant testą ranku ergometru, pirmas ir antras VS, juos atitinkančios absoliučios VE ir ŠSD reikšmès, absoliučios ir santykinès $\mathrm{VO}_{2}$ reikšmès buvo mažesnès $(\mathrm{p}<0,05)$, negu atliekant NDK veloergometru ir bėgtakiu. Santykinès ŠSD reikšmès ties pirmu ir antru VS nesiskyrè, lyginant darbo skirtingais ergometrais duomenis (2 lent.).

Bègikų VS ir dauguma juos atitinkančių vegetacinių sistemų funkcinių rodiklių buvo didžiausi bėgant, mažesni dirbant veloergometru, mažiausi - rankų ergometru (3 lent.).

Dauguma irkluotojų rodiklių buvo didžiausi bėgant, mažesni - atliekant NDK veloergometru ir rankų ergometru (4 lent.). Idomu tai, kad šioje grupèje užfiksuota nedaug skirtumų tarp rodikliu dirbant rankų ergometru ir veloergometru.
2 lentelè. Dviratininkų vegetacinès sistemos submaksimalios reikšmès ties ventiliaciniais slenksčiais atliekant nuosekliai didinamo krūvio testą veloergometru, rankų ergometru, bėgtakiu (pateikiami imčių vidurkiai ir standartiniai nuokrypiai)

Pastaba. ${ }^{\wedge}$ - reikšmingas rodiklių skirtumas $(\mathrm{p}<0,05)$ atliekant testą veloergomertu ir bėgtakiu;

* - veloergometru ir rankų ergometru; \# - rankų ergometru ir bėgtakiu.

3 lentelè. Bègikų vegetacinès sistemos submaksimalios reikšmès ties ventiliaciniais slenksčiais atliekant nuosekliai didinamo krūvio testą veloergometru, rankų ergometru, bėgtakiu (pateikiami imčiu vidurkiai ir standartiniai nuokrypiai)

Pastaba. ${ }^{\wedge}$ - reikšmingas rodiklių skirtumas $(\mathrm{p}<0,05)$ atliekant testą veloergomertu ir bėgtakiu,

* _ veloergometru ir rankų ergometru, \# - rankų ergometru ir bėgtakiu.

\begin{tabular}{|c|c|c|c|}
\hline Tiriamieji & & Dviratininkai & \\
\hline Rodiklis & Veloergometrija & Rankų ergometrija & Bègtakis \\
\hline VS 1, W & $226,86(28,52)^{\wedge}$ & $82,71(2,81)^{*}$ & $190,29(17,87) \#$ \\
\hline VS $1, \mathrm{~W} / \mathrm{kg}$ & $3,15(0,40)^{\wedge}$ & $1,18(0,21)^{*}$ & $2,60(0,34) \#$ \\
\hline VE ties VS $1,1 / \mathrm{min}$ & $61,76(11,68)^{\wedge}$ & $42,61(6,84)^{*}$ & $71,71(11,65) \#$ \\
\hline ŠSD ties VS 1, tv. / min & $149,48(8,57)$ & $136,51(9,47)^{*}$ & $155,90(12,25) \#$ \\
\hline ŠSD ties VS 1 nuo ŠSD ${ }_{\max }, \%$ & $77,13(2,64)$ & $77,32(7,18)$ & $82,25(13,04)$ \\
\hline $\mathrm{VO}_{2}$ ties $\mathrm{VS} 1,1 / \mathrm{min}$ & $2,94(0,66)$ & $1,38(0,22)^{*}$ & $2,83(0,24) \#$ \\
\hline $\mathrm{VO}_{2}$ ties $\mathrm{VS} 1, \mathrm{ml} / \mathrm{min} / \mathrm{kg}$ & $37,07(7,49)$ & $19,91(2,89)^{*}$ & $40,81(5,84) \#$ \\
\hline $\mathrm{VO}_{2}$ ties VS 1 nuo $\mathrm{VO}_{2 \max }, \%$ & $64,96(10,51)$ & $51,75(4,73)^{*}$ & $63,15(5,16) \#$ \\
\hline VS 2, W & $307,71(20,2)^{\wedge}$ & $118,71(8,98)^{*}$ & $255,86(27,14) \#$ \\
\hline VS 2, W / kg & $4,29(0,47)^{\wedge}$ & $1,66(0,24)^{*}$ & $3,48(0,31) \#$ \\
\hline VE ties VS 2,1/ min & $89,71(12,08)^{\wedge}$ & $75,29(13,35)$ & $103,43(9,17) \#$ \\
\hline ŠSD ties VS 2, tv. / min & $176,10(10,09)$ & $160,95(7,55)^{*}$ & $182,33(9,73) \#$ \\
\hline ŠSD ties VS 2 nuo ŠSD ${ }_{\max }, \%$ & $90,72(2,48)$ & $91,13(3,18)$ & $91,42(4,03)$ \\
\hline $\mathrm{VO}_{2}$ ties $\mathrm{VS} 2,1 / \mathrm{min}$ & $3,70(0,43)$ & $1,92(0,15)^{*}$ & $3,70(0,26) \#$ \\
\hline $\mathrm{VO}_{2}$ ties $\mathrm{VS} 2, \mathrm{ml} / \mathrm{min} / \mathrm{kg}$ & $51,12(7,86)$ & $27,69(2,84)^{*}$ & $51,51(4,93) \#$ \\
\hline $\mathrm{VO}_{2}$ ties VS 2 nuo $\mathrm{VO}_{2 \max }, \%$ & $82,06(2,56)$ & $72,05(4,96)^{*}$ & $82,46(6,42) \#$ \\
\hline
\end{tabular}

\begin{tabular}{|c|c|c|c|}
\hline Tiriamieji & & Bègikai & \\
\hline Rodiklis & Veloergometrija & Rankų ergometrija & Bègtakis \\
\hline VS 1, W & $183,71(24,54)$ & $87,86(23,41)^{*}$ & 207 (22)\# \\
\hline VS $1, \mathrm{~W} / \mathrm{kg}$ & $2,46(0,37)$ & $1,17(0,30)^{*}$ & $2,80(0,53) \#$ \\
\hline VE ties VS $1,1 / \mathrm{min}$ & $56,95(11,41)$ & $51,38(10,15)$ & $70,43(9,37) \#$ \\
\hline ŠSD ties VS 1, tv. / min & $139,38(11,20)$ & $132,29(12,76)$ & $153,71(13,79) \#$ \\
\hline ŠSD ties VS 1 nuo ŠSD ${ }_{\max }, \%$ & $76,77(6,08)$ & $77,76(6,66)$ & $81,20(5,31)$ \\
\hline $\mathrm{VO}_{2}$ ties $\mathrm{VS} 1,1 / \min$ & $2,34(0,24)^{\wedge}$ & $1,71(0,17)^{*}$ & $3,20(0,22) \#$ \\
\hline $\mathrm{VO}_{2}$ ties $\mathrm{VS} 1, \mathrm{ml} / \mathrm{min} / \mathrm{kg}$ & $31,31(4,15)^{\wedge}$ & $24,04(3,22)^{*}$ & $42,59(4,05) \#$ \\
\hline $\mathrm{VO}_{2}$ ties VS 1 nuo $\mathrm{VO}_{2 \max }, \%$ & $57,55(8,82)$ & $58,60(6,65)$ & $67,49(4,84) \#$ \\
\hline VS 2, W & $260,57(24,1)$ & $125,57(16,7)^{*}$ & $290,86(38,7) \#$ \\
\hline $\mathrm{VS} 2, \mathrm{~W} / \mathrm{kg}$ & $3,48(0,34)$ & $1,68(0,26)^{*}$ & $3,92(0,72) \#$ \\
\hline VE ties VS $2,1 / \mathrm{min}$ & $81,57(10,07)^{\wedge}$ & $68,76(10,72)^{*}$ & $117,67(17,55) \#$ \\
\hline ŠSD ties VS 2, tv. $/$ min & $162,1(8,12)^{\wedge}$ & $148,9(11,11)^{*}$ & $175,0(7,73) \#$ \\
\hline ŠSD ties VS 2 nuo ŠSD ${ }_{\max }, \%$ & $89,41(6,30)$ & $87,53(5,27)$ & $92,58(3,20) \#$ \\
\hline $\mathrm{VO}_{2}$ ties $\mathrm{VS} 2,1 / \mathrm{min}$ & $3,10(0,27)^{\wedge}$ & $2,12(0,26)^{*}$ & $4,17(0,23) \#$ \\
\hline $\mathrm{VO}_{2}$ ties $\mathrm{VS} 2, \mathrm{ml} / \mathrm{min} / \mathrm{kg}$ & $41,86(4,71)^{\wedge}$ & $28,66(2,79)^{*}$ & $57,40(6,33) \#$ \\
\hline $\mathrm{VO}_{2}$ ties VS 2 nuo $\mathrm{VO}_{2 \max }, \%$ & $75,88(8,38)^{\wedge}$ & $72,76(8,43)$ & $87,94(6,45) \#$ \\
\hline
\end{tabular}




\begin{tabular}{|c|c|c|c|}
\hline Tiriamieji & & Irkluotojai & \\
\hline Rodiklis & Veloergometrija & Rankų ergometrija & Bègtakis \\
\hline VS 1, W & $179,29(18,75)^{\wedge}$ & $110,86\left(15,58^{*}\right.$ & $231,57(41,06) \#$ \\
\hline $\mathrm{VS} 1, \mathrm{~W} / \mathrm{kg}$ & $2,15(0,37)^{\wedge}$ & $1,34(0,16)^{*}$ & $2,80(0,45) \#$ \\
\hline VE ties VS $1,1 / \mathrm{min}$ & $53,86(10,40)^{\wedge}$ & $48,36(4,47)$ & $80,14(18,38) \#$ \\
\hline ŠSD ties VS 1, tv. / min & $139,81(12,23)^{\wedge}$ & $129,10(8,51)$ & $153,86(10,82) \#$ \\
\hline ŠSD ties VS 1 nuo ŠSD ${ }_{\max }, \%$ & $76,54(6,31)$ & $71,34(1,77)$ & $79,74(4,65) \#$ \\
\hline $\mathrm{VO}_{2}$ ties $\mathrm{VS} 1,1 / \min$ & $2,35(0,27)^{\wedge}$ & $1,88(0,26)$ & $3,43(0,52) \#$ \\
\hline $\mathrm{VO}_{2}$ ties $\mathrm{VS} 1, \mathrm{ml} / \mathrm{min} / \mathrm{kg}$ & $29,1(3,86)^{\wedge}$ & $23,17(2,14)$ & $43,29(5,14)$ \\
\hline $\mathrm{VO}_{2}$ ties VS 1 nuo $\mathrm{VO}_{2 \max }, \%$ & $54,72(6,53)^{\wedge}$ & $47,95(5,27)$ & $70,73(7,0) \#$ \\
\hline VS 2, W & $271,57(22,6)$ & $177,57(17,9)^{*}$ & $327,57(63,2) \#$ \\
\hline $\mathrm{VS} 2, \mathrm{~W} / \mathrm{kg}$ & $3,30(0,36)$ & $2,15(0,19)^{*}$ & $3,95(0,62) \#$ \\
\hline VE ties VS $2,1 / \mathrm{min}$ & $85,48(15,42)^{\wedge}$ & $79,29(7,94)$ & $120,0(22,61) \#$ \\
\hline ŠSD ties VS 2, tv. / min & $166,43(0,09)^{\wedge}$ & $160,10(12,77)$ & $177,71(7,34) \#$ \\
\hline ŠSD ties VS 2 nuo ŠSD ${ }_{\max }, \%$ & $91,07(3,42)$ & $87,76(4,23)^{*}$ & $92,14(3,23)$ \\
\hline $\mathrm{VO}_{2}$ ties $\mathrm{VS} 2,1 / \mathrm{min}$ & $3,37(0,27)^{\wedge}$ & $3,00(0,30)$ & $4,37(0,60) \#$ \\
\hline $\mathrm{VO}_{2}$ ties $\mathrm{VS} 2, \mathrm{ml} / \mathrm{min} / \mathrm{kg}$ & $41,14(3,90)^{\wedge}$ & $37,87(2,98)$ & $53,73(5,52) \#$ \\
\hline $\mathrm{VO}_{2}$ ties VS 2 nuo $\mathrm{VO}_{2 \max }, \%$ & $78,50(6,94)^{\wedge}$ & $76,75(7,74)$ & $90,18(6,36) \#$ \\
\hline
\end{tabular}

4 lentelè. Irkluotojų vegetacinès sistemos submaksimalios reikšmės ties ventiliaciniais slenksčiais atliekant nuosekliai didinamo krūvio testą veloergometru, rankų ergometru, bègtakiu (pateikiami imčių vidurkiai ir standartiniai nuokrypiai)

\section{REZULTATŲ APTARIMAS}

Tyrimo rezultatai rodo, kad atliekant NDK veloergometru, bejgtakiu ir ranku ergometru labiausiai nuo ergometrijos tipo ir tiriamojo lettosios adaptacijos ypatumu priklauso absoliučios VS reikšmès, mažiausiai - santykinès (procentais nuo maksimaliu) $\mathrm{VO}_{2}$ ir ypač ŠSD reikšmès ties VS.

Seniai žinoma, kad absoliučios maksimalios ir submaksimalios aerobinio pajègumo rodikliu reikšmès dirbant ranku ergometru yra mažesnès negu veloergometru ar bègtakiu, o veloergometru, išskyrus dviratininkų, reikšmès būna mažesnès nei dirbant bėgtakiu (Davis et al., 1976; Louhevaara et al., 1990). Specifiniai pokyčiai treniruojantis gali labiau pasireikšti testuojant submaksimalius negu maksimalius aerobinio pajègumo rodiklius (Pierce et al.,1990). Taigi lètoji adaptacija galètų sumažinti skirtumus tarp darbo skirtingais ergometrais, ypač analizuojant submaksimalius rodiklius. Tuo galima paaiškinti didžiausias dviratininkų VS reikšmes, jiems dirbant specifiškiausiu veloergometru, tačiau absoliučios VE, ŠSD, $\mathrm{VO}_{2}$ reikšmès ties abiem VS šioje grupejje buvo didesnès bėgant. Tai rodo didesni dviratininkų mechaninio darbo efektyvumą sukant veloergometro pedalus. Mūsų tyrimų rezultatai sutampa su M. M. Costa ir bendraautoriu (1989) gautaisiais, teigiančiais, kad bėgikų VS ir vegetacinių sistemų rodikliai ties VS buvo didesni atliekant testą bėgtakiu negu veloergometru. Irkluotoju vegetacinès sistemos submaksimalūs rodikliai buvo reikšmingai didesni atliekant testa bėgtakiu negu ranku ergometru ir veloergometru. Manome, kad tai galèjo lemti didesnè dirbančiu raumenu masè. Panašius skirtumus pastebejjo
V. Bunc ir J. Leso (1993), tyrę irkluotojus veloergometru ir irklavimo ergometru. Jie pastebejo, kad nors irkluotojams specifinis yra irklavimo ergometras, bet VS reikšmès buvo didesnès atliekant testą veloergometru. Nėra tyrimų, kurių metu būtų nagrinėjami bėgiku ir dviratininku vegetaciniu sistemu rodikliai ties VS, atliekant testus ranku ergometru. Dar labiau adaptacijos specifiškumas matyti analizuojant ryšius tarp VS dydžiu, kai NDK atliekamas skirtingais ergometrais. Jei irkluotoju pirmas VS dirbant rankomis sudaro $47 \%$ šio rodiklio reikšmès bėgant, tai bėgiku - 43\%, dviratininku - tik 37\% reikšmès užfiksuotos sukant veloergometro pedalus. Rodikliu skirtumas tarp darbo ranku ir kitais ergometrais išlieka visose grupèse. Tai, matyt, labiausiai susiję su skirtinga dirbančių raumenu mase, kuri sukant rankenas yra mažesnè negu bėgant ar sukant veloergometro pedalus.

Idomu ir tai, kad santykinès $\mathrm{VO}_{2}$ reikšmès ties VS bėgiku grupèje buvo didžiausios atliekant jiems specifišką krūvi bėgtakiu. Tiesa, baidarių irkluotoju grupejje šis rodiklis taip pat didžiausias bėgant, o dviratininkų bėgant ir sukant veloergometro pedalus panašus. Visose grupèse šis rodiklis buvo mažiausias dirbant rankų ergometru. Santykinis $\mathrm{VO}_{2}$ dydis ties VS rodo perejimo nuo grynai aerobinès prie vis labiau anaerobinès ATP resintezès, atliekant NDK, ypatumus. Šis peréjimas anksčiausiai prasideda dirbant rankomis (Pendergast et al., 1979). Tai gali lemti didesnis greitujų raumenų skaidulų kiekis dirbančiuose viršutinès kūno dalies raumenyse, o baidariu irkluotoju grupeje - dar ir specifinis greituju skaidulų treniravimas jègos ir jègos ištvermès bei anaerobiniais fiziniais krūviais. 
Mažiausiai nuo ergometro tipo mūsų tyrimo metu priklausė santykinès ŠSD reikšmès ties VS, ypač ties antru, nors absoliučios ŠSD reikšmès ties šiomis intensyvumo ribomis buvo mažiausios dirbant rankų ergometru, didžiausios — bègant. Tik bėgikų minèti slenksčiai pasireiškẻ esant šiek tiek didesniam maksimalaus ŠSD procentui. Tai rodo, kad iš santykiniu ŠSD reikšmiu geriau nei iš absoliučiu galima nustatyti aerobinio darbo intensyvumo ribas, atliekant krūvị skirtingo tipo ergometrais, nors ir šiuo atveju gali paveikti specifinè lètoji adaptacija. Kaip nustatè F. A. Basset ir M. R. Boulay (2000), ŠSD esant panašiam $\mathrm{VO}_{2 \max }$ procentui yra panašus dirbant veloergo- metru ir bėgant. Atlikto tyrimo duomenys rodo, kad ŠSD santykiniai dydžiai mažiau priklauso nuo ergometro tipo ir tiriamujų lètosios adaptacijos specifikos negu santykiniai $\mathrm{VO}_{2}$ dydžiai.

\section{IŠVADA}

Atliekant NDK veloergometru, bėgtakiu ir rankų ergometru labiausiai nuo ergometrijos tipo ir tiriamojo lètosios adaptacijos specifikos priklauso absoliučios VS reikšmès, mažiausiai santykinès (procentais nuo maksimaliu) $\mathrm{VO}_{2}$ ir ypač ŠSD reikšmės ties VS.

\title{
LITERATŪRA
}

Basset, F. A., Boulay, M. R. (2000). Specificity of treadmill and cycle ergometer tests in triathletes, runners and cyclists. European Journal of Applied Physiology, 81 (3), $214-221$.

Bunc, V., Leso, J. (1993). Ventilatory threshold and work efficiency during exercise on a cycle and rowing ergometer. Journal of Sports Science, 11 (1), 43-48.

Costa, M. M., Russo, A. K., Pićarro, I. C. et al. (1989). Oxygen consumption and ventilation during constant-load exercise in runners and cyclists. Journal of Sports Medicine and Physical Fitness, 29 (1), 36-44.

Davis, J. A., Vodak, P., Wilmore, J. H., Vodak, J., Kurtz, P. (1976). Anaerobic threshold and maximal aerobic power for three modes of exercise. Journal of Applied Physiolo$g y, 41$ (4), 544-550.

Louhevaara, V., Sovijärvi, A., Ilmarinen, J., Teräslinna, P. (1990). Differences in cardiorespiratory responses during and after arm crank and cycle exercise. Acta Physiologica Scandinavica, 138 (2), 133-143.
Pendergast, D., Cerretelli, P., Rennie, D. W. (1979). Aerobic and glycolytic metabolism in arm exercise. Journal of Applied Physiology, 47 (4), 754-760.

Pierce, E., Weltman, A., Seip, R., Snead, D. (1990). Effects of training specificity on lactate threshold and $\mathrm{VO}_{2}$ peak. International Journal of Sports Medicine, 11, 267-373.

Plato, P. A., McNulty, M., Crunk, S. M., Tug Ergun, A. (2008). Predicting lactate threshold using ventilatory threshold. Journal of Sports Medicine, 29 (9), 732-737.

Schneider, D. A., Lacroix, K. A., Atkinson, G. R., Troped, P. J., Pollack, J. (1990). Ventilatory threshold and maximal oxygen uptake during cycling and running in triathletes. Medicine and Science in Sports and Exercise, 22 (2), 257-264.

Weltman, A. (1995). The Blood Lactate Response to Exercise. Champaign, IL: Human Kinetics. P. 1-117.

\section{THE INFLUENCE OF ADAPTATION SPECIFICITY AND ERGOMETRY MODE ON SUBMAXIMAL PARAMETERS OF AEROBIC CAPACITY}

\author{
Inga Pravdinskienè, Arvydas Stasiulis, Aleksandras Alekrinskis \\ Lithuanian Academy of Physical Education, Kaunas, Lithuania
}

\begin{abstract}
The aim of the study was to compare the submaximal parameters of aerobic capacity during different modes of graded exercise tests in runners, cyclists and kayakers.

Seven cyclists (age $-19.7(2.5)$ years, height $-1.82(0.66) \mathrm{m}$, weight $-74.3(10.0) \mathrm{kg}, \mathrm{BMI}-$ 22.5 (1.9), seven runners (age - 22.6 (4.1) years, height $-1.84(0.52) \mathrm{m}$, weight -75.1 (5.8) $\mathrm{kg}, \mathrm{BMI}-$ $22.2(1.8))$ and seven kayakers (age $-20(1.2)$ years, height $-1.84(0.67) \mathrm{m}$, weight $-82.6(5.1) \mathrm{kg}$,
\end{abstract}


BMI - 24.5 (1.3) on different days performed graded exercise tests (GXT) on treadmill, cycling or arm ergometers. The gas exchange parameters were recorded breath-by-breath using analyser "Oxycon Mobile" (Germany), the heart rate (HR) — using "Polar S810" (Finland) HR monitor.

In cyclists group the absolute values of ventilatory thresholds (VT) were dependent on the type of ergometer used: the highest values were during cycling, the lowest - during arm ergometry. Pulmonary ventilation (VE) heart rate (HR), $\mathrm{VO}_{2}$ at VT demonstrated greatest changes during treadmill test. During arm ergometry VT, VE and HR at VT, absolute and relative $\mathrm{VO}_{2}$ values were lower but relative HR at both VT were similar then those during running and cycling. In runners group VT and most cardiorespiratory parameters were the highest during running and the lowest during arm ergometry. In kayakers group many parameters were the highest during running as compared with cycling and arm ergometry. In this group there were not many differences between parameters measured during cycling and arm cranking.

It is concluded that during cycling, running and arm ergometry GXT the absolute values of VT are more dependent on the type of ergometry and on the specificity of adaptation then relative (as \% of maximal values) $\mathrm{VO}_{2}$ and especially $\mathrm{HR}$ values.

Keywords: specificity of adaptation, ventilatory thresholds, oxygen uptake, heart rate, mode of ergometry.

Gauta 2009 m. gegužès 5 d.

Received on May 5, 2009

Priimta 2009 m. gegužès 26 d.

Accepted on May 26, 2009

Inga Pravdinskienè

Lietuvos kūno kultūros akademija

(Lithuanian Academy of Physical Education)

Sporto g. 6, LT-44221 Kaunas

Lietuva (Lithuania)

Tel +370 37302671

E-mail balticsand@gmail.com 